\title{
E-university delivery model: handling the evaluation process
}

\author{
Rasha Ismail \\ College of Business, American University of the Middle East, Kuwait City, Kuwait \\ Fadi Safieddine \\ School of Business and Management, \\ Queen Mary University of London, London, UK, and \\ Ashraf Jaradat \\ College of Business, American University of the Middle East, Kuwait City, Kuwait
}

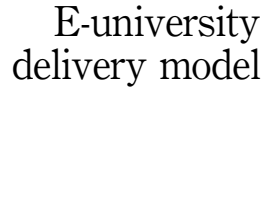

1633

Received 3 October 2018 Revised 9 December 2018 Accepted 16 December 2018

\begin{abstract}
Purpose - The setting up of e-university has been slow-going. Much of e-university slow progress has been attributed to poor business models, branding, disruptive technologies, lack of organisational structure that accommodates such challenges, and failure to integrate a blended approach. One of the stumbling blocks, among many, is the handling of evaluation process. E-university models do not provide much automation compared to the original brick-and-mortar classroom model of delivery. The underlining technologies may not have been supportive; however, the conditions are changing, and more evaluation tools are becoming available for academics. The paper aims to discuss these issues.

Design/methodology/approach - This paper identifies the extent of current online evaluation processes. In this process, the team reviews the case study of a UK E-University using Adobe Connect learning model that mirrors much of the physical processes as well as online exams and evaluation tools. Using the Riva model, the paper compares the physical with the online evaluation processes for e-universities to identify differences in these processes to evaluate the benefits of e-learning. As a result, the models can help us to identify the processes where improvements can take place for automating the process and evaluate the impact of this change.

Findings - The paper concludes that this process can be significantly shortened and provide a fairer outcome but there remain some challenges for e-university processes to overcome.

Originality/value - This paper examines the vital quality assurance processes in academia as more universities move towards process automation, blended or e-university business models. Using the case study of Arden University online distance learning, the paper demonstrates, through modelling and analysis that the process of online automation of the evaluation process is achieved with significant efficiency.
\end{abstract}

Keywords Process efficiency, E-learning, Virtual organizations, Riva model, Virtual learning

Paper type Research paper

\section{Introduction}

In the age of information, more universities are seeking new forms of learning platforms and communication channels. These communication channels need to meet the needs and expectations of students who already use similar applications in their everyday activities. Several universities have gradually sought to automate or move operations online. Innovation, interaction, collaboration are key elements along with technology-driven initiatives. In fact, Tapscott and Williams (2010) suggest user-generated media, social networking, crowdsource and peer production for the new university concept using mass collaboration is the new form of

(C) Rasha Ismail, Fadi Safieddine and Ashraf Jaradat. Published by Emerald Publishing Limited. This article is published under the Creative Commons Attribution (CC BY 4.0) licence. Anyone may reproduce, distribute, translate and create derivative works of this article (for both commercial and non-commercial purposes), subject to full attribution to the original publication and authors. The full terms of this licence may be seen at http://creativecommons.org/licences/by/4.0/legalcode

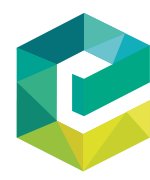

Business Process Management Journal 25 No. 7,2019
pp. $1633-1646$ pp. 1633-1646
Emerald Publishing Limited
$1463-7154$ DOI 10.1108/BPMJ-10-2018-0281 
BPMJ

25,7

1634

online collectivism. In a publication on e-universities, Ismail et al. (2017) looked at technological trends in e-universities as well as handling lectures/lessons in the context of the larger picture of university processes. In this respect, evaluation handling is an important element in moving forward the concept of e-university. This paper presents a review of the literature with regards to the evaluation process of e-universities. The paper uses two unique case studies of physical and virtual evaluation handling processes. Then, the paper reflects on improvements and limitations of the move towards virtual classroom within an e-university process.

\section{Literature review}

With the advancement of internet, Bergstrand and Savage (2013) suggest that universities and colleges are increasingly motivated toward e-universities format. In this context, virtual or online education can be implemented, and courses can be offered with larger enrolments and smaller budgets. A survey by Allen and Seaman (2014) of 2,500 US colleges and universities showed that $5.6 \mathrm{~m}$ students were enrolled in at least one online class.

Various terms and concepts are found in the higher education literature to refer to online courses. Online courses are referred to as distance (online) learning, e-learning, e-universities, virtual universities and Web 2.0-based education (Safieddine et al., 2017). All of these electronic forms of higher education institutions seek and support the same fundamental mission of the traditional (i.e. campus base) university such as teaching, research and society services (Burnett and Natalia, 2010). The virtual education blends the benefits of technology with the wisdom of traditional learning, and with efficient design, development and delivery. In this context, Lee et al. (2003) suggest that an online university needs to deliver every aspect of the conventional university to the online or virtual environment including teaching, processes, structures, working place, staffing, administration, support, aid, assessments, evaluations and services.

Therefore, online universities should consider incorporating a proper education methodology that highly relies on advance information, technology and artificial intelligence (AI). The aim for these universities is to offer quality online courses with the virtual content creation and distribution, administration, attendances, assessments, exams, proctoring, grading and evaluations aspects (Wong, 2012). In fact, all the mentioned aspects rely on an interactive communication among different university's members and parties, such as instructors, learners/students, head of departments, registers and exam unit. According to Tapscott and Williams (2010), it is crucial that there is interactive and virtual information flow process, where different parties and information's types and forms could be involved in the process.

\subsection{E-university evolution}

Distance or online education has been developing for decades, where various research and commercial models and systems were proposed by many Academics in the literature such as Atoum et al. (2017), Al-Musharraf and Alkhattabi (2016), Nerkar (2017), Sarrayrih and Ilyas (2013), Yamakawa et al. ( 2008) and Rogers (2006) to name a few. Bacsich (2005) reported that in the e-commerce boom of early 2000 the UK secretary of education declared the formation of UK e-University (UKeU). Only four years later, the project was declared as a public failure, and the project was abandoned. In reflection on their experience, Bacsich (2005) presented some of the reasons for the failures. These reasons included the importance of branding, poor business models, disruptive technologies, lack of organisational structure that accommodates such challenges, failure to integrate a blended approach and appreciation that many of the applicants are from countries where English is not their first language. Failure to integrate a blended approach is seen as an important factor here as it refers to the experience that student got from a virtual university and their expectations to how higher education processes take place in the real environment. 
There is an increased cost in higher education and relative reduction in the cost of technology in comparison. Bergstrand and Savage (2013) suggest that there has been a renewed interest in the online university to provide different ways of knowledge delivery, thus helping higher education institutions to cope with bigger enrolments and smaller budgets. E-university can follow either the asynchronous or synchronous learning approach (Feldman and Zucker, 2015). Earlier, e-university researchers had based their work on the asynchronous learning approach, where time-delayed limitations of the internet were accepted. Wu and Bieber (2008) explain asynchronous learning approach as involving tools like e-mail, threaded discussion, newsgroups and bulletin boards, and file attachment. In contrast, recent research efforts toward e-university are based on the synchronous learning approach, such as the research conducted by Atoum et al. (2017), Al-Musharraf and Alkhattabi (2016) and Nerkar (2017). This approach aims to enable groups that are separated in time and space to engage in the active production of shared knowledge. Synchronous learning approach is not a new term in teaching. Synchronous learning was defined by Gunawardena et al. (1997) as instruction and collaboration in real time via the internet. Synchronous learning approach mode of e-university typically involves many tools. These tools include live chat, audio and video conferencing, data and application sharing, shared a whiteboard, virtual "hand raising", and joint viewing of multimedia presentations and online slideshows.

Humanante Ramos et al. (2015) explain this new mode of e-university where information and advanced communication technologies are integrated into the educational field forces a new revolution. A revolution in the way we conceive learning experiences compared to the traditional way. It offers several advantages over the traditional one, such as it saves the learner time and reduces his/her education cost. It can give more flexibility, convenience and equal opportunities to learners. It also provides innovative teaching and rich contents delivery methods and forms to its students, which can range from motion pictures, animations, web-accessible material to virtual reality (VR) materials. Also, Humanante Ramos et al. (2015) suggest that technology can help reduce the environmental cost by cutting the use of paper as well as the transport. Therefore, internet, VR and AI tools can be a dominant infrastructure for knowledge sharing among people and a new generation of virtual universities (Safieddine, 2017).

In earlier work, the authors have examined the technological trends that have opened up new opportunities for e-universities and followed this with the first look at key processes involved in moving from physical to virtual lecturer delivery. This paper looks at the assessment and evaluation processes manifested in examinations with a specific look at online exams as a key stepping stone towards fully reliable e-universities.

\subsection{Online evaluation}

According to Wang (2011), education serves two main purposes; transferring knowledge, skills and abilities to learners, and awarding credentials to students. These credentials have to be based on some effective and reliable examinations and assessments of learning outcomes. Educators strive to keep finding objective and creative ways of testing students' knowledge that can add value to the learner, rather than considering it as an unpleasant interruption (Wu and Bieber, 2008).

The work of Sarrayrih (2016) examines post-exam and assessment evaluations as an important quality assurance component for many educational programs, where well-designed and reliable evaluation process is an essential part of such education processes. Sarrayrih (2016) suggests that performing online evaluation depends on the reliability of the technology to be able to improve and enhance the review process compared to the traditional processes that use papers and pens.

According to Palea et al. (2017), evaluation is an academic concept that exceeds the definition of measure and the appreciation of students' performance. It is a process of 
BPMJ

25,7

1636

assessing and determining learning outcomes throughout revealing the contribution of the modalities of improvement of the outcome-objective relationship, and of each resource in the training process. Evaluation is essential for teaching and learning activities, as it helps to identify and measure individual learning achievements and to indicate lecture improvements (Usener et al., 2012). Evaluation is, therefore, a crucial element in any assessment as it represents judgment and provides students with information concerning the correctness of responses in sort of letter grades, percentile scores, number of solved items, etc.

According to Russell and Airasian (2012), the most common type of evaluation that students receive in a typical classroom is grades. Grades provide a convenient summary of students' performance, inform all interested parties of students' achievement and provide grounds for making critical educational decisions. Furthermore, grades support the students' administrative and registration purpose. Grades also help counsellors to provide guidance and motivations to students.

In a study of the evaluation process of Iranian nursing students, Vaismoradi and Parsa-Yekta's (2010) findings suggest that assessment of learning is highly correlated to the factual objectivity of the assessments grades. Hence, a proper evaluation can be an arduous task fraught with indecision and frustration. The main concern for students as well as their instructors is the lack of consistency and uncertainty in the traditional (human) evaluation process. Various types of errors related to the traditional evaluation process, such as the HALO effect, the gentle effect, the generosity error, the Pygmalion effect and the contamination effect, are further identified and explained in the works of Palea et al. (2017) and Stangl (2013). And while there is no suggestion in the literature that automating evaluation will remove all these problems completely, the authors of this paper believe that the automation of evaluation will most definitely reduce the likelihood of such problems. Consequently, applying digital/automatic grading can improve the objectivity of the assessment's evaluation.

In fact, a proper evaluation of students affects their learning performance. Hence, the works of Wang et al. (2008) and Taşci et al. (2014) suggest the elimination of human evaluation's error and subjectivity by utilising and executing a proper computerised assessment and grading will positively affect student performance and satisfaction.

According to Hearst (2000), researchers in online distance learning and e-universities are in support of automated assessment systems and computerised grading approaches. This support has been influenced by the advancements in the field of natural language processing and information extraction. The work of Shuhidan and Mohamad (2013) suggests a variant of computerised grading functions, approaches and systems are being implemented around the world. Common types of these computerised grading are presented in Shuhidan and Mohamad (2013) and Siddiqi and Harrison (2008) and address questions like multiple choices, true/false, matching and fill-in-the-blank, while others such as CRASE, BETSY, C-rater addressed open-ended questions, i.e. short answer and essay questions. Furthermore, Shuhidan and Mohamad (2013) and Suh et al. (2010) explain that systems such as Stack Overflow, Answers.com, Formspring and Dahlia go beyond the computerised grading to address the evaluation of student responses.

\subsection{Limitations in the literature review}

The existing literature managed to introduce several effective evaluation tools to deliver several aspects of the traditional evaluation processes with the aim of ensuring and maintaining the quality and integrity of the assessment process. However, current literature overlooks a very important element involving the information flow. Understanding and tracking the type and flow of the information transferred between the participated entities within the evaluation process is a crucial aspect of ensuring the quality and effectiveness of the online evaluation. Moreover, comparing the online evaluation process against the 
traditional one may give further understanding and values towards the utilisation of virtual classroom and exams. This aspect is a chain of information process that includes the exam preparation, approval, proctoring, marking and grading, and results analysis. Key to these processes is that the information is delivered or transferred between different entities with different authorisation levels, such as course coordinator, other course instructions, head of department, dean, exam unit, registrar. Accordingly, this paper focusses on the information flow of handling the automated online evaluation process.

2.3.1 Process modelling. In order to understand the flow of data and differentiate between that in an online evaluation as opposed to physical evaluation, there is a need of process modelling. According to Beeson et al. (2009), the process modelling helps identify processes in two different ways: an abstract model and a detailed model. The aim is to provide a link between the designing of the processes and the final implementation. In the abstract model, an overall picture of the institution's processes is suggested. This is followed by the detailed model, where every process could be investigated independently.

The generated model would help present a prototype for the flow of work and the flow of information, allowing better visualisation and identification of an area of improvement, as demonstrated in Fady and Beeson's (2010) work. Process modelling can be used to break an institution's activity down into small processes made up of actions and interactions. The modelled processes can then be analysed and identify improvements.

2.3.2 Riva model. The Riva method of process modelling, first introduced by Martyn (2005), has a focus on the business rather than the application aspects of the system. In doing so, Riva looks at the process entities through the actions and interactions of different roles, rather than software logic.

Riva can, therefore, be used to model traditional scholastic processes and compare that to the e-university educational system while focussing on the key process of the evaluation process. The retrieved diagram is the overview process architecture that explains the core educational processes are ignoring any designed processes that are not essential to the educational process.

Riva technique is one of the techniques that are used to understand organisations' processes and activities. Riva allows users to generalise and speculate on how these models could be mapped onto different organisations that are operating in similar environments. Therefore, Riva method will support the study to map the traditional academic system to the e-university system. While doing so, we may find some processes are deducted, modified or added.

Part of the Riva method, the paper will present the Role Activity Diagramming of "Evaluation handling" Process to appreciate the detailed activities in this process. Role activity diagram is based on the necessary entities that represent the core of the administrative processes, also known as essential business entities (EBEs). It should be noted, however, that EBEs are not sufficient to fully represent all aspects of the processes within an organisation. Therefore, designers might need to review their processes in a different way to get their work done, in this case, Martyn (2005) referred to this as designed business processes (DBEs). However, the organisations cannot disregard DBEs from being included in their model.

The most important entities that the institution cannot remove are selected in the EBE to represent what Riva calls: units of work (UOWs). UOWs are tracked to become either case process $(\mathrm{CP})$ or case management process (CMPs). If we have a lot of $\mathrm{CP}$ cases, then they might need management and a CMP is added to the plan. CMP help us organise and arrange the processes before sending them to the $\mathrm{CP}$. The end diagram shows the interactions and the relationships between CPs and CMPs. Accordingly, the focus in this research is on the evaluation process. The process is analysed based on the data collected and observed from two universities; one is running the traditional lecturing and the second one is running it virtually.

2.3.3 Information flow for universities in higher education. In the case study presented in the work of Ismail and Abd El Aziz (2015), the authors presented a detailed review of the 
BPMJ

25,7

1638

physical processes of The Arab Academy for Science, Technology and Maritime Transport (AASTMT) in Egypt. The case looked at the essential learning processes at the College of Management and Technology of AASTMT. The case study was able to compare different learning processes in different universities and different countries, thus proving that they are comparable if not the same. The paper concluded that the same learning processes are used across different institutions. Therefore, the same process and technology improvements may be applicable and equally beneficial.

In Figure 1 we present that Second-Cut Process architecture Diagramming $(\mathrm{PAD})$ or the Detailed PAD showing the process architecture in Higher Education. The diagram provides an overview of the essential business of the college and how it allows mapping and query networks between different processes. This model allows visualisation of the workflow we expect to see in most higher education institutions. A detailed explanation of these processes found in the work of Ismail and Abd El Aziz (2015). We can see from Figure 1 that we have four key processes that are essential for institutions in higher education: "handle a course curriculum", "handle a lecture", "handle an assessments/exams", and "handle of evaluation". In this paper, the main focus is on "handle of evaluation" process. The process is selected as it is seen as a core part of the educational system for which the remaining processes are associated and serving it as well as a key gap identified in the literature with regards to a fully integrated e-university realisation. A list may be presented with each item marked by bullets and numbers.

Handling of the evaluation process is a challenging representation when comparing the traditional and virtual learning process as it is a challenging process to be undertaken virtually. The process starts when the managing of the flow of handling exams and/or assessments which would include the assessment criteria and takes into account curriculum requirements, the instructor then starts handling the evaluation. After the process is finished by the end of the semester, the instructor is required to provide feedback on the performance; this feeds into the curriculum and appeal processes. A detailed study of this process is the key to understanding how this transition can take place.

\section{Methodology}

This paper aims to design a virtual and integrated e-university process model to visualise the handling of evaluation as the essential process of any e-university process. This process to explore the available technologies and find a system that mirrors much of physical processes into a virtual environment. For this to be completed, the authors agreed on the methodology to follow these defined research objectives:

(1) to conduct a literature review of existing models for e-university;

(2) to identify gaps in the literature with regards to key process modelling;

(3) to model the processes of evaluation handling of a real university;

(4) to model and study the processes of an online evaluation process; in this case, the team selected the online classroom model of Arden University;

(5) validate and compare these processes for completeness, similarities, and differences; and

(6) make recommendations for improvements and changes.

Hence, the alternative and null hypotheses of this paper are as follows:

$H_{1}$. There is a measurable improvement in the handling of evaluation processes between physical and online university model.

$H_{0}$. There is no measurable improvement in the handling of evaluation processes between physical and online university model. 


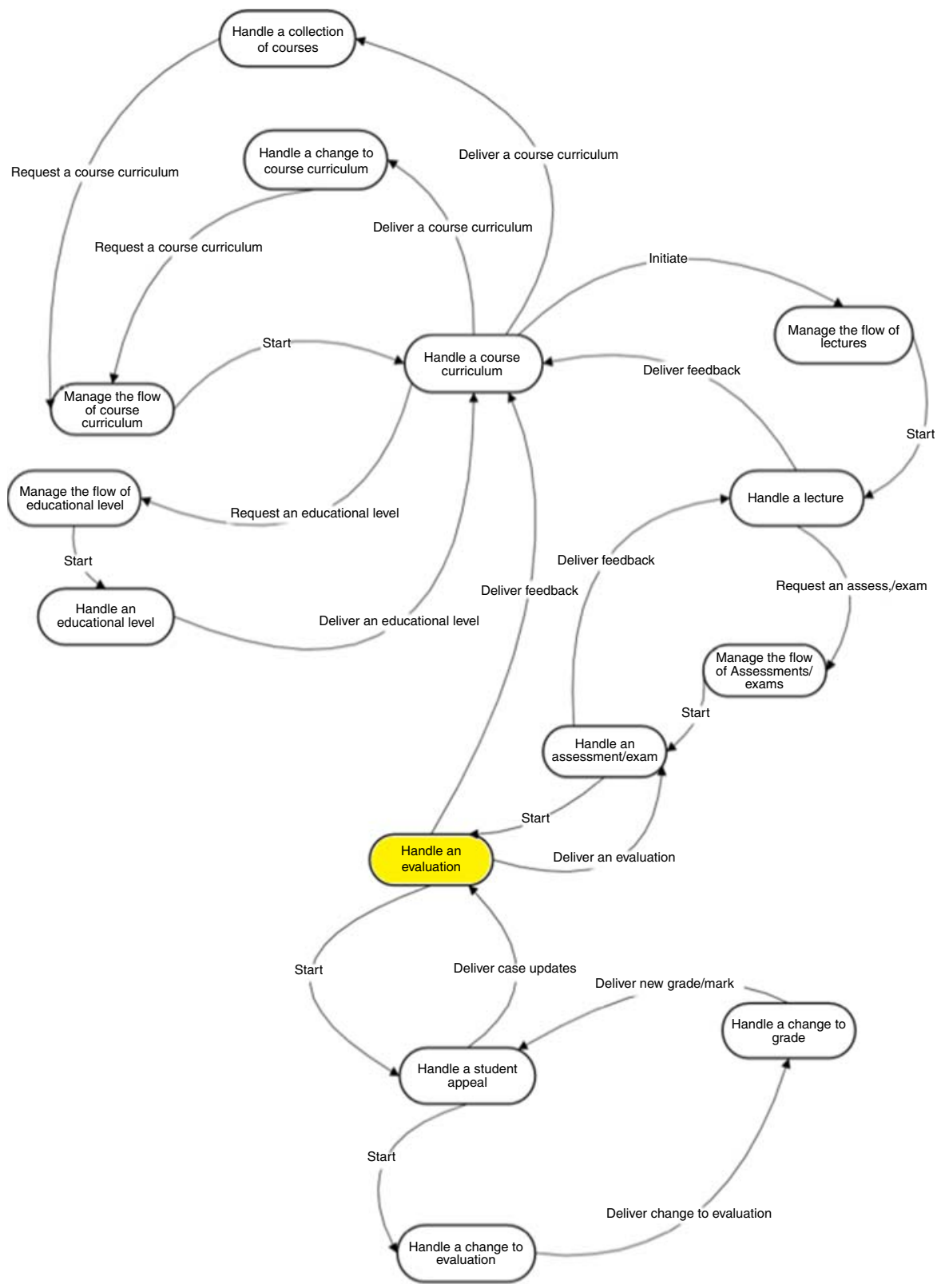

E-university
delivery model

1639

Source: Ismail and Abd El Aziz (2015)

Figure 1.

Detailed PAD for higher education system

The measurement of improvement is by means of qualitative analysis that would consider a possible reduction in redundant processes, faster delivery, higher security, reduction in cost and/or reduction of errors, ultimately resulting in an overall enhanced consideration of quality assurance of the given process. 
BPMJ

25,7

1640

From the literature review, the authors have been able to complete Objectives 1 and 2 . Further work will be needed to analyse the assessment delivery processes at AASTMT to complete Objective 3. For Research Objective 4, the authors will review the educational processes of Arden University as a case of a blended teaching university with strong leniency to the e-university model. Arden University online courses use Adobe Connect, a tool demonstrated in Cappiccie and Desrosiers (2011), as well as the information collated from the literature on the handling of evaluations online. These processes will be closely examined alongside AASTMT lesson delivery processes for verification and completeness to complete Objective 5. Finally, for Objective 6, the team will make their recommendations for improvements.

\section{Modelling: "handling and evaluation" process}

The two diagrams below illustrate the activities, information and roles for "handle an evaluation" process both traditionally and online.

\subsection{Traditional evaluation process}

Figure 2 shows the traditional manual activities that are done to evaluate an exam's papers. In this process, the exam instructor has to collect the exam papers from the control room after counting them. Using the answer key of the exam, the instructor will start correcting the exam question after another until all the questions are corrected then the total mark will be calculated and added to the cover page. The instructor continues to do the same process to each exam paper until all the papers of the exam are corrected.

Each exam needs to be peer-reviewed by another instructor by taking a sample to the exam to make sure there are no mistakes and for quality assurance purposes. In case a mistake is found, it will be reported and corrected. Otherwise, the instructor will be informed that there are no mistakes. In all cases, the instructor will start to enter the grades on Moodle in Excel sheets, then prepares the grade report. The results are then sent to the head of the department to approve for publishing it to the students. The head will also send the results to the registration office to review the grades on the system towards those on papers. If there is any mistake, they need to report it to the head of the department to take corrective action. The head will pass it to the instructor to fix it and update the results. The new change will then be sent by the head to the registration to be registered on the system.

In case if there is an appeal from a student, this will be processed in the "handle a student appeal", "handle a change to evaluation" and "handle a change to grade" processes. In this case, the instructor will need to update the results documents to reflect the change that took place.

\subsection{The online approach to "evaluation process"}

Figure 3 shows the online activities that are taking place to evaluate an exam paper. Information about the exam enters the system by the student when he/she starts to answer online. Also, the answer key of the exam is located on the system. While the student is taking the exam and adding answers to the questions the system corrects the questions right after the answers are submitted to the system. After that, the system calculates the total exam mark, stores it, adds it to the rest of the course's marks and finds the equivalent letter grade. The grade is shared with the registration system to calculate the GPA of the student and then share it with the student online. The system will also prepare a result report and shares it with the team leader.

\subsection{Information flow in the educational system}

One important issue in educational systems is the integration of information about one single course/student. The student will be allowed to take the exam only if the information 


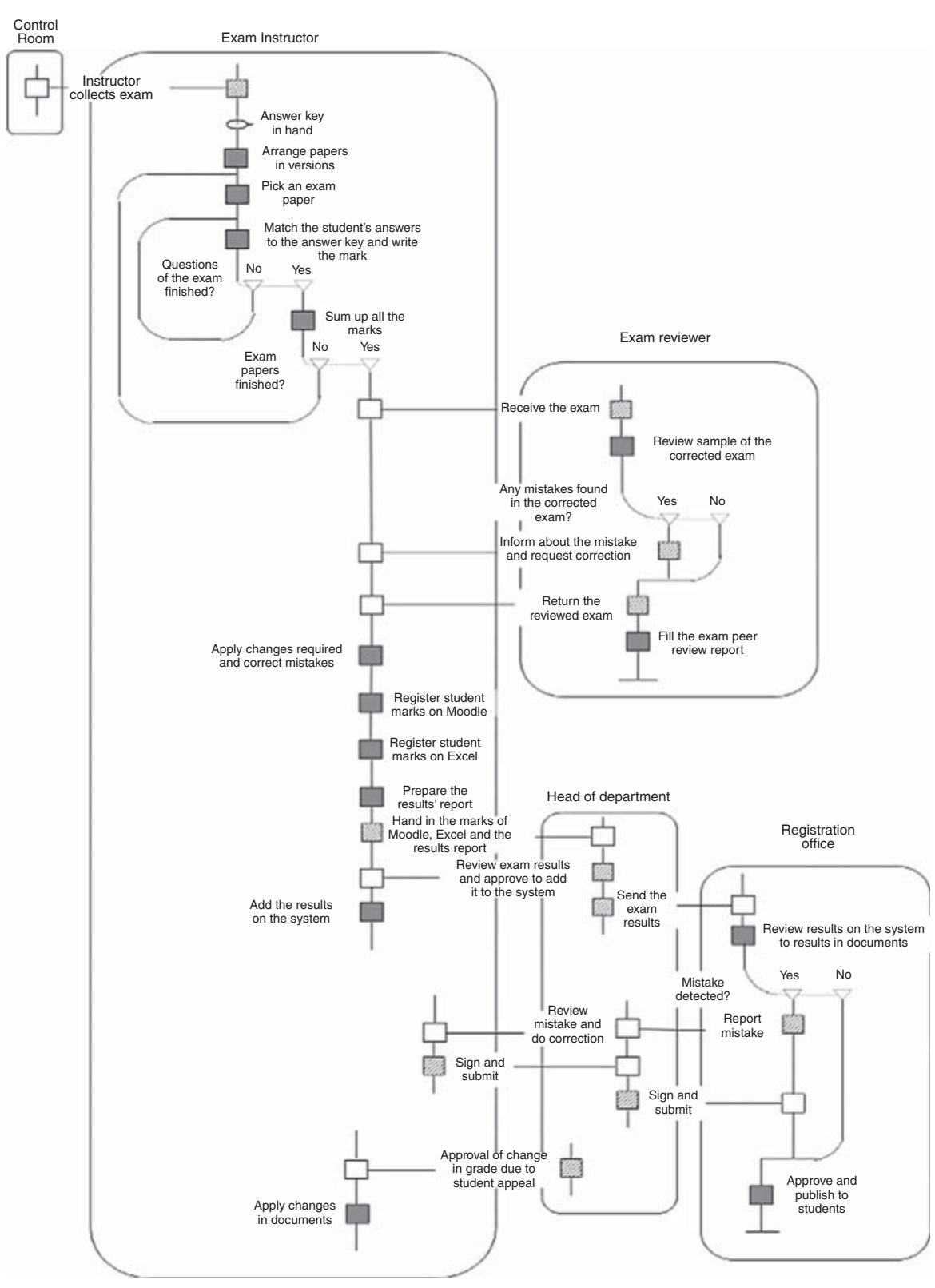

Figure 2.

Handle an evaluation (traditional process)

on the system indicates that he/she had already registered in the course and paid the fee. Also, the attendance of the students in the exam will be taken once they log in to the system, this indicates that each student who attends an exam should get a mark. Every student who is registered in the course but did not attend the exam should get incomplete and so on. Part of the integration of courses is also related to the questions of the exam and the answer key provided for the question, the maximum marks and the obtained marks, etc. 
BPMJ

25,7

1642

Figure 3.

Handle an evaluation (online process)

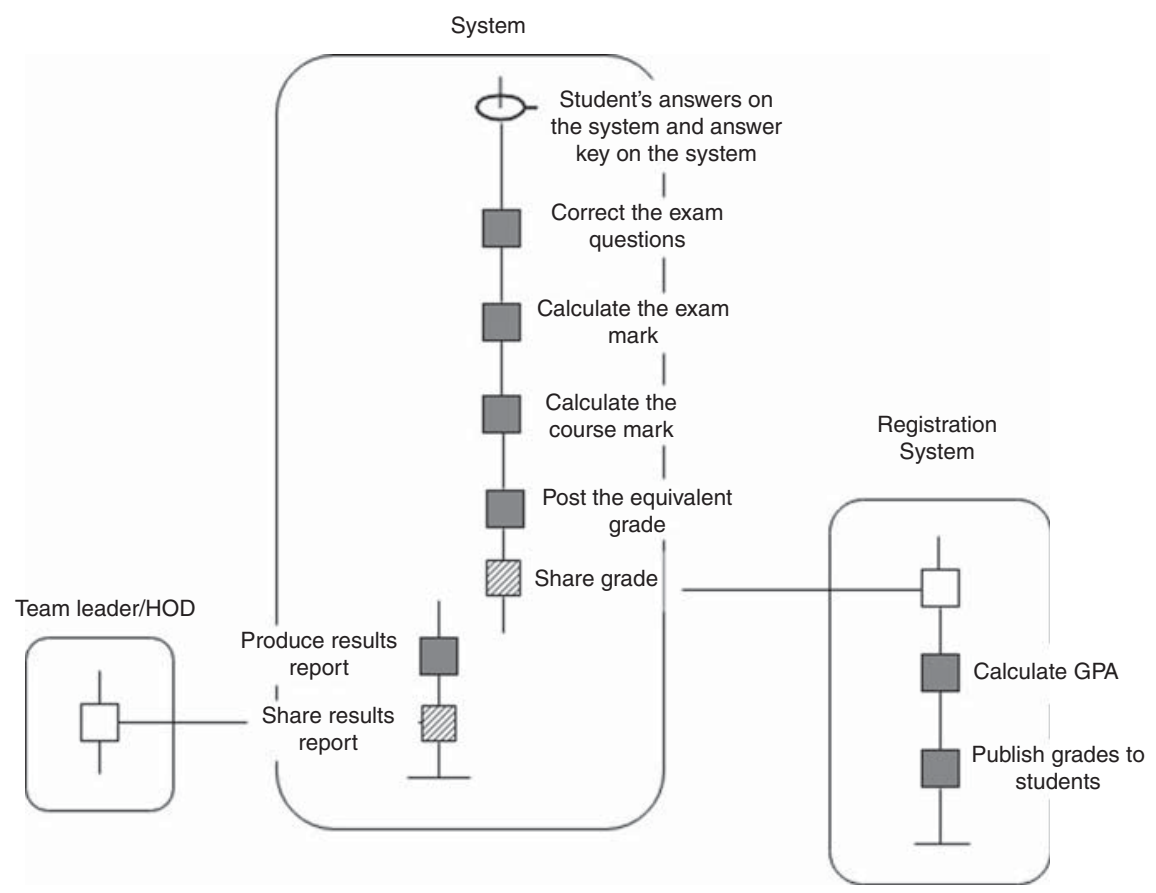

The higher the quality of information, the less the activities and the mistakes that are expected to happen.

\section{Analysis}

Tables I and II show the flow of data for each process based on the analysis of data flow from Figures 2 and 3. It demonstrates that the flow of data in the online system happens completely electronically. Electronic data sharing reduces the physical movement of data from one party to another and thus reduces mistakes that can happen while doing so. The availability of data on a centralised system allows the sharing of same data that speeds up the process rather than going through routine procedures to access it. On the other hand, the results can be published to students once the exam is corrected without any human intervention that reduces mistakes that tend to happen when physically copying grades from sheets. There are also more activities that take place in the traditional system in order to approve results like reviewing them towards the Excel sheets before publishing them. The system will eliminate mistakes produced when multiple data entry takes place also errors that happen during the calculation of the students' marks will be eliminated.

\begin{tabular}{llll}
\hline Data description & From & To & Type \\
\hline Answer key & System & System & Electronic \\
Mark of the question & System & System & Electronic \\
Total exam mark & System & System & Electronic \\
Total course mark & System & System & Electronic \\
Letter grade & System & System/Registration system & Electronic/online \\
Results report & System & Team leader/Head of department & Electronic \\
\hline
\end{tabular}

Results report
Table I.

Data flow for online processes for the evaluation process 


\begin{tabular}{|c|c|c|c|c|}
\hline Data description & From & To & Type & delivary \\
\hline Physical exam & Control room & Instructor & Paper & \\
\hline Answer key & Instructor & Instructor & Paper & \\
\hline Mark of each question & Instructor & Exam paper & Paper & \\
\hline Total exam mark & Instructor & Exam paper & Paper & \\
\hline Peer-reviewed mistakes & Reviewer & Instructor & Oral & \\
\hline Peer-reviewed report & Reviewer & Head of the department & e-mail & 1643 \\
\hline Changes in correction & Instructor & Exam paper & Paper & \\
\hline Students marks & Instructor & Moodle & Electronic & \\
\hline Student marks & Instructor & Excel & Digital & \\
\hline Result report, Excel results and Moodle results & Instructor & Head of the department & Paper & \\
\hline Approval to post results on the system & Head of the department & Instructor & Oral & \\
\hline Results on the system & Instructor & System & Electronic & \\
\hline Exam results & Head of department & Registration office & Paper & \\
\hline A mistake in results on the system & Registration office & Head of the department & Paper & \\
\hline A mistake in results on the system & Head of the department & Instructor & Paper & \\
\hline Corrected result & Instructor & Head of department & Paper & \\
\hline Corrected result & Head of the department & Registration office & Paper & Tabl \\
\hline Publish corrected result & Registration office & System & Electronic & Data flow \\
\hline Approved new grade of student appeal & Head of the department & Instructor & e-mail & for traditional \\
\hline Change new grade & Instructor & Documents & $\begin{array}{l}\text { Digital/ } \\
\text { paper }\end{array}$ & $\begin{array}{l}\text { processes for the } \\
\text { evaluation process }\end{array}$ \\
\hline
\end{tabular}

Based on the analysis of "handle an evaluation" process both traditionally and online, it is clear that the number of activities in the online process (11 activities) is less than those in the traditional process (37 activities). This big difference is due to the automation of the activities and the automation of data transfer. Many activities are eliminated in the traditional system like repeated checks, changing the grade and posting the grades on the system. Automating the evaluation process reduces the need for human intervention in a sensitive process reducing human errors and facilitating speed of process.

Based on this qualitative analysis, it is evident that $H_{0}$ cannot be supported as there is sufficient evidence the processes of Figure 3, which is further elaborated in Table I, demonstrate a reduction in the number of processes from 37 under physical conditions to 11 under online conditions. There is also sufficient qualitative analysis to suggest that the online process will significantly reduce the time in which these processes take place. The cost and security risks do not appear to change. The human factor remains the most dominant risk in both models. Therefore, there is no evidence that the online method has a negative impact on the quality assurance of the evaluation processes. Thus, suggesting that $H_{1}$ is valid under these conditions.

\section{Conclusion}

The objective of this paper is to examine the vital quality assurance processes in academia as more universities move towards process automation, blended or e-university models. As demonstrated, this analysis shows that the process of online automation of the evaluation process is achieved using the case study of Arden University online courses.

After the analysis of the process for both universities, it is clear that the implementation of "handle and evaluation" in the online system is more efficient and effective at delivering than the traditional approach. Both models are compared, and the flow of data is also analysed that revealed more automation in data transfer and less human intervention.

However, this is only one of several processes that the team had modelled. There remain other aspects, shown in Figure 1, that need to be done for the other processes. In addition, 
BPMJ

25,7

1644

there needs to be a critical review of the other processes to truly appreciate the concept of a fully integrated online e-university experience. Other essential processes that the team intends to investigate are the "handle of curriculum" and "handle of assessments". Beyond demonstrating theoretically, the efficiency of automated online processes of blended and e-university processes, we remain mindful of the lessons learned from the failure of the UKeU. Vital to this analysis is the concept of trust and validity of the process.

Further research is needed to compare the outcome from classes, modules and courses taught in physical and virtual moods of studies. Will students and employers give the same weight to qualifications earned via e-university degree as they do from traditional university degree? What will be the key to the trust in this process? What are the lessons learned from comparing the online process with the physical process that could be used to enhance the whole process? Furthermore, the team agree that there should be a survey in the form of a questionnaire that would examine the views of academics on the issue of moving the evaluation process online. This survey to also look at concerns related to academic quality assurances and enhancements.

\section{References}

Allen, I.E. and Seaman, J. (2014), Gra de Change: Tracking Online Education in the United States, Babson Survey Research Group and Quahog Research Group, Wellesley, MA.

Al-Musharraf, A. and Alkhattabi, M. (2016), "An educational data mining approach to explore the effect of using interactive supporting features in an LMS for overall performance within an online learning environment", International Journal of Computer Science and Network Security, Vol. 6 No. 3, pp. 1-13.

Atoum, Y., Chen, L., Liu, A.X., Hsu, S.D. and Liu, X. (2017), “Automated online exam proctoring”, IEEE Transactions on Multimedia, Vol. 19 No. 7, pp. 1609-1624.

Bacsich, P. (2005), "Lessons to be learned from the failure of the UK e-university", The Open and Distance Learning Association of Australia Conference, Adelaide, November.

Beeson, I., Green, S. and Kamm, R. (2009), "Process architectures in higher education", Academy for Information Systems Conference, AISeL, London, 31 March.

Bergstrand, K. and Savage, S.V. (2013), "The chalkboard versus the avatar: comparing the effectiveness of online and in-class courses", American Sociological Association in collaboration with JSTOR, Vol. 41 No. 3, pp. 294-306.

Burnett, D. and Natalia, C. (2010), "Higher education for our time", Journal of Computing in Higher Education, Vol. 22 No. 3, pp. 192-198.

Cappiccie, A. and Desrosiers, P. (2011), "Lessons learned from using Adobe Connect in the social work classroom”, Journal of Technology in Human Services, Vol. 29 No. 4, pp. 296-302.

Fady, R.I. and Beeson, I. (2010), "Drawing out the essential business of ports", IBIMA Business Review, Vol. 2010, 11pp.

Feldman, R. and Zucker, D. (2015), "Teaching and learning online: communication, community, and assessment”, available at: www. umass.edu/oapa/oapa/publications/online_handbooks/ Teaching_and_Learning_Online_Handbook.pdf (accessed 21 February 2018).

Gunawardena, C.N., Lowe, C.A. and Anderson, T. (1997), "Analysis of a global online debate and the development of an interaction analysis model for examining social construction of knowledge in computer conferencing", Journal of Educational Computing Research, Vol. 17 No. 4, pp. 397-431.

Hearst, M.A. (2000), "The debate on automated essay grading", IEEE Intelligent Systems and their Applications, Vol. 15 No. 5, pp. 22-37.

Humanante Ramos, P.R., García-Peñalvo, F.J. and Conde-González, M.A. (2015), "Personal learning environments and online classrooms: an experience with university students", IEEE Revista Iberoamericana de Tecnologías del Aprendizaje, Vol. 10 No. 1, pp. 26-32. 
Ismail, R., Safieddine, F. and Kulakli, A. (2017), "E-university lecture delivery model: from classroom to virtual", International Conference on IEEE Engineering \& MIS (ICEMIS), pp. 1-7, available at: http://dx.doi.org/10.1109/ICEMIS.2017.8272983 (accessed 8 May 2017).

Ismail, R.F. and Abd El Aziz, R. (2015), "Using ICT to improve the Egyptian higher education business processes: a case study", Journal of Organizational Studies and Innovation, Vol. 2 No. 3, pp. 25-38.

Lee, I., Im, Y., Heo, H. and Chun, S. (2003), "Searching for academic and organizational model of e-universities", EdMedia: World Conference on Educational Media and Technology. Association for the Advancement of Computing in Education (AACE), Honolulu, HI, 23 June.

Martyn, O. (2005), Business Process Management: A Rigorous Approach, Meghan-Kiffer Press, BCS, Swindon.

Nerkar, M.P. (2017), "Online exam proctoring system (completely automated proctoring solution)", International Journal of Advance Engineering and Research Development, Vol. 4 No. 1, pp. 10-12.

Palea, L., Boștina-Bratu, S. and Negoescu, A. (2017), "Fundamental aspects of evaluation in the context of enhancing the quality of the educational act", Journal of Social-Behavioral Sciences, Vol. 4 No. 88 , pp. 233-238.

Rogers, C. (2006), "Faculty perceptions about e-cheating during online testing", Journal of Computing Sciences in Colleges, Vol. 22 No. 2, pp. 206-212.

Russell, M.K. and Airasian, P.W. (2012), Classroom Assessment: Concepts and Applications, McGraw-Hill, Blacklick, $\mathrm{OH}$.

Safieddine, F. (2017), "M-commerce", in Seifedine, K. and Abdelkhalak, E.H. (Eds), Innovations in e-systems for Business and Commerce, Chapter 7, CRC, Oakville.

Safieddine, F., Ismail, R. and Kulakli, A. (2017), "E-universities: a reflective analysis of technological trends", IADIS 15th International Conference on e-Society, Budapest, 10 April.

Sarrayrih, M. (2016), "Implementation and security development online exam, performances and problems for online university exam", International Journal of Computer Science and Information Security, Vol. 14 No. 1, pp. 24-33.

Sarrayrih, M. and Ilyas, M. (2013), "Challenges of online exam, performances and problems for online university exam", International Journal of Computer Science Issues, Vol. 10 No. 1, pp. 439-443.

Shuhidan, S.M. and Mohamad, A. (2013), "Dahlia: online formative assessment for theoretical course", The 3rd International Conference on Research and Innovation in Information Systems (ICRIIS'13), pp. 510-515.

Siddiqi, R. and Harrison, C.J. (2008), "On the automated assessment of short free-text responses", The 34th International Association for Educational Assessment (IAEA) Annual Conference, Cambridge, 7 September.

Stangl, W. (2013), "HALO effect”, Lexikon für Psychologie und Pädagogik, Vol. 3 No. 7, pp. 50-54.

Suh, B., Hong, L., Pirolli, P. and Chi, E.H. (2010), "Want to be retweeted? Large scale analytics on factors impacting retweet in Twitter network", IEEE Social Computing (socialcom), 20 August, pp. 177-184.

Tapscott, D. and Williams, A.D. (2010), "Innovating the 21st-century university: it's time!", Educause Review, Vol. 45 No. 1, pp. 16-29.

Taşci, T., Parlak, Z., Kibar, A., Taşbaşi, N. and Cebeci, H.İ. (2014), "A novel agent-supported academic online examination system”, Journal of Educational Technology \& Society, Vol. 17 No. 1, pp. 154-168.

Usener, C.A., Majchrzak, T.A. and Kuchen, H. (2012), "E-assessment and software testing”, Interactive Technology and Smart Education, Vol. 9 No. 1, pp. 46-56.

Vaismoradi, M. and Parsa-Yekta, Z. (2010), "Iranian nursing students' comprehension and experiences regarding evaluation process: a thematic analysis study", Scandinavian Journal of Caring Sciences, Vol. 25 No. 1, pp. 151-159. 
BPMJ

25,7

Wang, H. (2011), "Creditable learning assessment in internet-based distance education: a protocol for online supervised examination with authentication", The International Conference on E-Learning, E-Business, Enterprise Information Systems, \& E-Government, Las Vegas: NV, pp. 471-477.

Wang, T.H., Wang, K.H. and Huang, S.C. (2008), "Designing a web-based assessment environment for improving pre-service teacher assessment literacy", Computers \& Education, Vol. 51 No. 1, pp. 448-462.

Wong, D.H. (2012), "Reflections on student-university interactions for next generation learning", Asia Pacific Journal of Marketing and Logistics, Vol. 24 No. 2, pp. 328-342.

Wu, D. and Bieber, M. (2008), "Engaging students with constructivist participatory examinations in asynchronous learning networks", Journal of Information Systems Education, Vol. 19 No. 3, pp. 321-330.

Yamakawa, Y., Peng, M.W. and Deeds, D.L. (2008), "What drives new ventures to internationalize from emerging to developed economies?", Entrepreneurship Theory and Practice, Vol. 32 No. 1, pp. 59-82.

\section{About the authors}

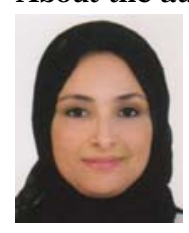

Dr Rasha Ismail is Associate Professor at the College of Business Administration, American University of the Middle East. Her research interests are in e-learning, information system management, business analysis and business process management.

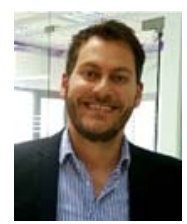

Dr Fadi Safieddine is Senior Lecturer and Accreditation Manager at the School of Business and Management, Queen Mary University of London. His research interests are in management information systems, e-learning modelling, business processes, and big data modelling of misinformation on social media. Dr Fadi Safieddine is the corresponding author and can be contacted at: f.safieddine@qmul.ac.uk

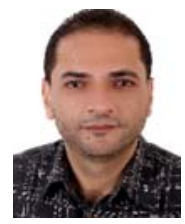

Dr Ashraf Jaradat is Assistant Professor at the College of Business Administration, American University of the Middle East. His research interest in information system modelling, data integration, data fusion, uncertainty management, e-learning modelling and knowledge management.

For instructions on how to order reprints of this article, please visit our website: 